\title{
ИСТОРИЧЕСКАЯ НАУКА
}

\author{
Е. Л. Храмкова
}

\section{Рецензия на монографию: \\ Буранок С. О. «Куйбышев - \\ запасная столица СССР: \\ образ города в англо-американском \\ обществе 1941-1945 гг.» ${ }^{1}$}

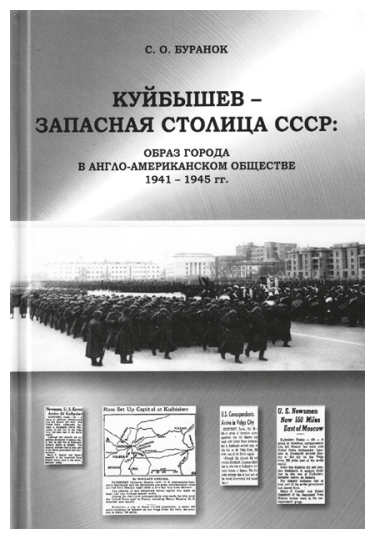

Хралкова Елена

Ленаровна

доктор исторических

наук, профессор,

Самарский

государственный

социально-

педагогический

университет

(Самара, Россия)
Появление рецензируемой монографии вызвано актуализацией локальной истории в отечественной историографии, формированием новых представлений о месте и роли российских регионов, в частности, в наиболее значимых события XX столетия, а также обращением исследователей к сложной проблеме взаимовосприятия народов ${ }^{2}$.

Книга затрагивает вопросы методологического, источниковедческого, конкретно-исторического и терминологического характера, связанные с формированием англо-американским сообществом образа города Куйбышева (ныне - Самары) как «запасной столицы» нашей страны в 1941-1943 гг.

Данная тема не являлась предметом научного анализа ни в отечественной, ни в зарубежной историографии, однако контуры ее изучения были намечены С. О. Буранком в монографических ${ }^{3}$, документальных ${ }^{4}$ и других публикациях ${ }^{5}$.

Образ Куйбышева рассматривается в хронологическом ключе, что позволило автору проследить процесс постепенного накопления сведений о запасной столице в англо-американском обществе, показать трансформацию представлений о городе на протяжении военного периода. 
Структура монографии не вполне типична и обусловлена общей авторской концепцией. Книга состоит из двух частей: 1) аналитической; 2) документальной, включающей публикацию мемуаров англо-американских авторов с комментариями и примечаниями автора. Подборка дипломатических документов также с авторскими ремарками содержится в «Приложении». Завершает книгу фотоальбом. Такая композиция исследования настраивает читателя не только на ознакомление с выводами и замечаниями, содержащимися в первой части, но и на самостоятельное, вдумчивое прочтение подлинных документов военного времени, дает возможность согласиться или поспорить с автором по поводу некоторых оценок. Сочетание разделов приводит к появлению не только обобщенного образа «второй столицы», когда-то существовавшего в общественном мнении союзников СССР и навсегда запечатленного в дошедших до наших дней архивных и опубликованных материалах, но и глубоко личного образа города, сложившегося у отдельных представителей посольств США и Соединенного Королевства Великобритании и Северной Ирландии, иностранных журналистов и фотокорреспондентов во время их пребывания в Куйбышеве в 1941-1943 гг. При совмещении оба образа дают возможность увидеть общие и особенные черты запасной столицы, выступающей в общественном мнении англо-американцев в качестве одного из символов воюющего с фашистской Германией СССР.

Во введении монографии раскрываются актуальность и новизна проведенного исследования в контексте общесоюзной (общероссийской), региональной отечественной историографии, самарского краеведения, а также источниковедения проблемы ${ }^{6}$.

С. О.Буранок, безусловно, прав, привлекая внимание заинтересованных специалистов к возможностям, которые открылись благодаря использованию новых источников и методологических подходов при изучении одной из традиционных тем в поволжской историографии - «Куйбышев военных лет». На рубеже XX-XXI вв. были выявлены малоизвестные аспекты проблемы, что способствовало приращению исторических знаний по местной истории в частности и советской истории в целом ${ }^{7}$. Однако практически незамеченным остался вопрос о возможности реконструкции образа запасной столицы как «многофакторного и противоречивого процесса в общественно-политической жизни» США и Англии, «на стыке (в рамках имагологического подхода) "воображаемой географии" и "воображаемого сообщества"»8.

В достаточно подробном историографическом обзоре представляют интерес охарактеризованная автором традиционная схема, касающаяся изложения пребывания иностранных дипломатов в Куйбышеве, а также отмеченные пробелы в осмыслении темы, связанные с недостаточным изучением зарубежных источников ${ }^{9}$.

Что касается имагологического подхода, в рамках которого выполнено рецензируемое научное исследование, то, по мнению С. О. Буранка, он заключается в анализе «не только общего образа "советского союзника"», но и «конкретных практик и методик по его формированию на примере образа... города на Волге...»; с помощью этого подхода «актуализировались приоритетные черты восприятия СССР» общественностью стран-союзников ${ }^{10}$. 
Значимое место в авторской концепции занимает проблема исторической и культурной памяти, что нашло отражение в попытке рассмотрения Куйбышева (Самары) как нового центра советско-английских и советско-американских отношений в условиях Второй мировой войны ${ }^{11}$, в выявлении интересных фактов, свидетельствующих о достаточно длительном сохранении определенных «образов-воспоминаний», например, в американском кинематографе ${ }^{12}$.

Особый интерес представляет источниковая база исследования, на основе которой прослежен механизм формирования образа Куйбышева в англо-американском обществе военных лет, - как на непосредственном, во многом эмоциональном уровне эвакуированных из Москвы представителей дипломатического корпуса, журналистов, фотокорреспондентов, так и на уровне иностранных читателей.

Опираясь на принцип целевого предназначения, С.О.Буранок объединил выявленные источники в три основные группы.

Первую группу составили материалы американской прессы (197 наименований газет и журналов). Были исследованы как самые крупные и влиятельные издания (среди них - New York Times, Los Angeles Times, Chicago Daily Tribune, Washington Post), так и десятки газет средних и малых городов, издававшиеся более чем в 40 штатах. Автор обнаружил разночтения в подаче материалов и оценке советско-американских отношений, роли Куйбышева как одного из центров сотрудничества СССР и стран-союзниц в газетах различной партийной ориентации. Широко привлекалась также американская журнальная периодика военных лет. Анализ публикаций о Куйбышеве в зарубежной печати лег в основу авторских выводов об этапах и методах формирования у англо-американской общественности образа запасной столицы, стереотипов города, представлений о событиях, происходивших в нем.

Разнообразие изученных материалов печати, связанных с характером, периодичностью, политической ориентацией и другими факторами, обусловило реконструкцию многопланового и неоднозначного образа Куйбышева, представленного в прессе США и Великобритании.

Во вторую группу источников вошли документы американского и английского посольств, в которых с разной степенью полноты освещаются место и роль Куйбышева в событиях Второй мировой войны. Интересующие автора материалы были выявлены в Отделе устной истории Библиотеки Трумэна, Библиотеке Рузвельта, Отделе рукописей Библиотеки Конгресса США. Это записи интервью работников посольств в Куйбышеве, корреспонденция, сообщения, отчеты, информационные заметки, содержащие описания города, личные впечатления о нем.

Не менее ценной является и третья группа - источники личного происхождения. Как отмечено в монографии, к наиболее интересным из них относятся воспоминания Эдди Гилмора, Генри Кэссиди, Уоллеса Кэрролла, Джорджа Кеннана, Чарльза Тейера и некоторых других, оставивших разнообразные зарисовки быта иностранцев в Куйбышеве, характерных черт второй столицы, ее населения, развития промышленности и т.д.

В работе были использованы изобразительные источники, представленные кино- и фотодокументами, а также плакатами. Часть из них хранится в Национальном 
архиве США. Особенно интересен отмеченный автором факт отражения Куйбышева военного времени в голливудском кино ${ }^{13}$.

Формирование образа Куйбышева в монографии прослеживается не только с помощью указанных источников, но и на основе анализа материалов радиовещания, хранящихся в Библиотеке Конгресса США.

Изученные С. О. Буранком источники позволили решить поставленные в исследовании задачи, а также развернуть перед читателем целую галерею образов запасной столицы, сложившихся в англо-американском обществе в военный период.

Первая часть книги, состоящая из трех разделов, содержит анализ восприятия Куйбышева в прессе США и Великобритании, начиная с первых упоминаний о городе и до окончания Второй мировой войны.

В первом разделе первой части отмечается, что до нападения фашистской Германии на СССР англо-американская печать давала крайне скудную информацию о Куйбышеве и Куйбышевской области, однако дореволюционная история города освещалась с начала 1850-х гг. Наибольшее количество публикаций о Самаре приходится на время трех русских революций и Гражданской войны. По подсчетам автора, в это время информация о волжском городе появлялась в англо-американской прессе каждые четыре дня ${ }^{14}$. Ситуация изменилась с началом Великой Отечественной войны. Так, накануне эвакуации из Москвы правительственных учреждений и дипломатического корпуса дипломаты Великобритании и США попытались, в частности, выяснить информацию о месте, где им предстояло жить и работать. Как установил автор, первое упоминание Куйбышева относится к 18 октября 1941 г., когда пять американских газет опубликовали краткие сообщения о прибытии в город иностранных дипломатов. В них подчеркивалось отдаленность города на Волге от советской столицы ${ }^{15}$. Наиболее важную и оперативную информацию американская пресса получала от корреспондентов агентства Associated Press (Эдди Гилмор, Генри Шапиро, Уоллес Кэрролл, Генри Кэссиди), которые начали работать в запасной столице. Именно они сообщили новые сведения о городе, в том числе имена дипломатов, репортеров, фотокорреспондентов, прибывших в Куйбышев. На страницах американских газет появились первые фотографии волжского города, карты Поволжья, благодаря чему стал формироваться визуальный образ запасной столицы. С. О. Буранок обратил внимание на ошибки, неточности в информационных материалах как крупных центральных, так и провинциальных американских газет, которые были связаны со сложившимися штампами восприятия России, настроениями, доминировавшими среди проживавших в Куйбышеве журналистов, и другими причинами.

На основе фронтального просмотра ведущих американских газет автор пришел к выводу, что с 22 октября 1941 г. формируется целостный информационный поток, обеспечивающий быстрое распространение сведений географического, исторического, демографического, социально-экономического, военного и другого характера о временной столице среди широких слоев населения США ${ }^{16}$.

Второй и третий разделы первой части монографии посвящены проблеме усложнения и конкретизации образа города в общественном сознании англоамериканского общества в конце 1941-1943 гг. Автор отметил, что на страницах десятков американских и английских газет регулярно публиковались сведения 
с пометкой «из Куйбышева». В них подчеркивались стратегическое, индустриальное, дипломатическое значение и архитектурное своеобразие города (преобладание старых домов «с узорными деревянными наличниками» и одновременно наличие современных зданий ${ }^{17}$. Внимание зарубежных читателей, наверное, привлекали и жалобы сотрудников посольств США и Великобритании, содержащиеся в отдельных газетных материалах, например американского посла Л. Штейнхардта. Ему не понравилось просторное, но «убогое» (по словам дипломата) трехэтажное здание «дореволюционного винтажного стиля», которое было предоставлено посольству в Куйбышеве ${ }^{18}$.

Особое место в указанных разделах занимает анализ наиболее оригинальных газетно-журнальных статей по теме. Среди них автор выделил прежде всего статьи Э. Гилмора, одного из немногих иностранных журналистов, писавших не о собственных трудностях и лишениях, а о страданиях советского населения, о ночной жизни города, о работе театров ${ }^{19}$. Интересные сведения о быте дипломатов в Куйбышеве (в основном нелицеприятного характера) содержатся и в статье американского корреспондента Квентина Рейнольдса ${ }^{20}$.

Значительный интерес представляют высокие оценки американской прессой такого значимого события в культурной жизни Куйбышева и страны, как первое публичное выступление Д. Д. Шостаковича со своей Седьмой симфонией 5 марта 1942 г. Не оставили без внимания зарубежные корреспонденты несомненное пристрастие к театральным и музыкальным постановкам городской молодежи, что неудивительно: «Театр в Куйбышеве, - писал посол США в СССР Уильям Слейтер, - был тоньше, чем любой театр в Америке»21.

В заключении первой части автор сделал вывод об особенностях англо-американского взгляда на запасную столицу, включавшего достаточно многоплановые характеристики города во время войны.

Как уже отмечалось, во второй части книги опубликованы мемуары Э. Гилмора (1907-1967) 22 и Г. Кэссиди (1910-1988)23, содержащие новые сведения по рассматриваемой теме, а также позволяющие понять некоторые характерные черты восприятия советской военной действительности американскими журналистами.

Приложение включает ранее засекреченные документы, которые дают неизвестную и малоизвестную информацию об эвакуации и размещении дипломатического корпуса в Куйбышеве в начале Великой Отечественной войны; о репрезентации резервной столицы в англо-американской печати в контексте дореволюционной российской и советской истории, географического положения, климатических условий, промышленного, транспортного и культурного развития, изменившейся военно-политической ситуации в июне 1941 г. в связи с нападением фашистской Германии на СССР. Приведены документы, содержащие интересные наблюдения о повседневной жизни сотрудников иностранных посольств в Куйбышеве. Внимание привлекают так называемые «Самарские воспоминания», напечатанные 3 ноября 1941 г. в Time, где город фигурирует в качестве американского и самарского «места памяти». Речь идет об американской помощи голодающим волжанам в 1891 и 1921 гг. Безымянный автор сетовал на то, что население России всегда получало помощь от США с большим опозданием. Он также подметил, что ныне американское посольство «отсиживается в бывшей школе», его сотрудники 
неплохо питаются в тыловом городе и не ощущают то, что «должны были чувствовать в городской памяти», - «острую необходимость в помощи» ${ }^{24}$. В приложении XII «Отражение образа Куйбышева в фильме Дэлмера Дэйвса “Не отпускай меня"» (1953) рассматриваются малоизвестные факты, касающиеся проблемы отражения реалий военного Куйбышева в зарубежной кинопамяти.

Интересные материалы включены в фотоальбом, завершающий монографию. Это портреты работников посольства США и Великобритании в Куйбышеве, американских корреспондентов, коллаж на тему двух столиц (Москва - Куйбышев), первая фотография Куйбышева, которая была напечатана в американских газетах, обложки мемуаров, фотографии сообщений в англо-американской печати с упоминаниями города и др.

В целом англо-американский образ Куйбышева в монографии получился ярким, сложным, многогранным, во многом не совпадающим с нашими сегодняшними представлениями о запасной столице. Данный образ, пусть и «воображаемый», сохраняет значительную познавательную ценность: он отразил динамику восприятия не только отдельного города, региона, но и СССР в целом в общественном сознании американцев и британцев в условиях Второй мировой войны.

В заключение подчеркнем, что несомненной удачей автора является стиль изложения, сочетающий строго научный подход с научно-популярной подачей материала, что расширяет круг возможных читателей.

1 Буранок С.О. Куйбышев - запасная столица СССР: образ города в англо-американском обществе 1941-1945 гг.: монография / соавтор раздела I. 3 - Д.А. Ильин; подбор и публикация документов, комментарии и примечания - С.О.Буранок; пер. с англ. - С. Г. Малкин, Г. О. Щукина, Я.А. Левин, Е. В. Куликова. Самара: Изд-во СамНЦ РАН, 2016. 238 с.

2 Сенявский A. С., Сенявская Е. С. Историческая имагология и проблема формирования «образа врага» (на материалах российской истории XX в.) // Вестник РУДН. Сер. История России. 2006. № 2(6). С. 54-72; Поршнева О. С. Историческая имагология в современной российской историографии // Урал индустриальный. Бакунинские чтения. Индустриальная модернизация Урала в XVIII-XXI вв.: XII Всерос. науч. конф. Екатеринбург, 2014. Т.1. С.126-129; Лабутина T.Л. Актуальные проблемы исторической имагологии: историографический обзор // Югра, Сибирь, Россия: Политические, әкономические, социокультурные аспекты прошлого и настоящего: сб. науч. ст. Всерос. науч. конф. с междунар. участием. Нижневартовск, 2015. С.140143 и др.

3 «Мы» и «они»: Великая Отечественная война в оценках англо-американской общественности и современной историографии: монография / авт. колл.: С.О.Буранок, Ю.А. Никифоров, Д. В. Суржик, Д.А. Белов [и др.]. Самара, 2015.

4 Буранок С.О., Суржик Д.В., Белов Д.А. «Мы» и «они»: Великая Отечественная война в оценке общественности США и Великобритании: документы и материалы. Самара, 2014.

5 Буранок С. О.: 1) Куйбышев? Это конец света! // Самарские судьбы. 2011. № 1. С. 138$143 ; 2)$ Создание образа Куйбышева в американской прессе // Проблемы изучения военной истории: мат-лы Второй Всерос. науч. конф. Т.2. Самара, 2012. С. 89-96; 3) Американцы в СССР: оценки и восприятие г. Куйбышева военных лет // Вестник Адыгейского гос. ун-та. Сер. 1. Регионоведение: философия, история, социология, юриспруденция, политология, культурология. 2014. № 2 (139). С. 42-52; 4) Куйбышев - запасная столица в документах американских архивов // Проблемы изучения военной истории: сб. ст. Третьей Всерос. науч. конф. с междунар. участием. Самара, 2015. С. 305-310; 5) Создание образа Куйбышева в американской прессе // Человек 
и общество в условиях войн и революций: мат-лы III Всероссийской науч. конф. Самара, 2016. С. 238-244.

6 Буранок С. О. Куйбышев - запасная столица СССР... С. 4-16.

7 Дилитрова П. Донесения посланника царства Болгарии в СССР Ивана Стаменова как источник о жизни дипкорпуса в Куйбышеве (1941-1943 гг.) // Проблемы изучения военной истории: сб. ст. Третьей Всерос. науч. конф. с междунар. участием. Самара, 2015. С. 310-319; Захарченко A. B. Военный парад в Куйбышеве 7 ноября 1941 г. - новые источники и интерпретации (по материалам ГА РФ) // Там же. С. 323-327; Репинеикий А. И. «Запасная столица» на перекрестке войны и дипломатии (г. Куйбышев в годы Великой Отечественной войны) // Там же. С. 30-37; Христофборов В. С. Американские дипломаты на rendez-vous с советской политикой и культурой (1941-1945) // Quaestio Rossica. Екатеринбург, 2016. T. 4, № 1. С. 103-119; и др.

8 Буранок С. О. Куйбышев - запасная столица СССР... С. 11.

9 Там же. С. 7-8.

10 Там же. С. 4.

11 Там же. С. 5 .

12 Там же. С. 151-155.

13 Там же. С. 14-15.

14 Там же. С. 20-21.

15 Там же. С. 23.

16 Там же. С. 38-42.

17 Там же. С. 43-45 и др.

18 Там же. С. 46.

19 Там же. С. 55-57.

20 Там же. С. 67-70.

21 Там же. С. 66.

22 В монографию включены переведенные С.Г.Малкиным избранные главы по изданию: Gilmor E. Me and My Russian Wife. New York, 1954.

23 Перевод главы «Билет до Куйбышева» сделан Г. О. Щукиной по кн.: Cassidy H. Moscow Dateline: 1941-1943. Boston, 1943. P. 142-160.

24 Буранок С. О. Куйбышев - запасная столица СССР... С. 141.

\section{ДЛЯ ЦИТИРОВАНИЯ}

Храмкова Е. Л. Рецензия на монографию: Буранок С. О. «Куйбышев - запасная столица СССР: образ города в англо-американском обществе 1941-1945 гг.» // Новейшая история России. 2018. Т. 8. № 1. С. 218-225. https://doi.org/10.21638/11701/spbu24.2018.115

Сведения об авторе: Храмкова Е. Л. - д-р ист. наук, проф., Самарский государственный социально-педагогический университет (Самара, Россия); hramkova@rambler.ru

\section{FOR CITATION}

Khramkova E. L. 'Review of the monograph: Buranok S. O. "Kuybyshev - zapasnaja stolitsa SSSR: obraz goroda v anglo-amerikanskom obshchestve 1941-1945 gg."', Modern History of Russia, vol. 8, no. 1, 2018, pp. 218-225. https://doi.org/10.21638/11701/spbu24.2018.115

Author: Khramkova E. L. - Doctor of History, Professor, Samara State University of Social Sciences and Education (Samara, Russia); hramkova@rambler.ru

\section{References:}

Buranok S. O. 'Amerikancy v SSSR: ocenki i vosprijatie g. Kuybysheva voennykh let', Vestnik Adygeyskogo gosudarstvennogo universiteta, Ser. 1. Regionovedenie: filosofija, istorija, sociologija, jurisprudencija, politologija, kulturologija, no. 2 (139), 2014. 
Buranok S. O. 'Kuybyshev - zapasnaja stolica v dokumentakh amerikanskikh arkhivov', Problemy izuchenija voennoj istorii: sb. st. Tret'ej Vseros. nauch. konf. s mezhdunar. uchastiem. (Samara, 2015).

Buranok S. O. 'Kuybyshev? Eto konec sveta!', Samarskie sudby, no. 1, 2011.

Buranok S. O. 'Sozdanie obraza Kuybysheva v amerikanskoj presse', Problemy izuchenija voennoj istorii: mater. Vtoroj Vseros. nauch. konf., Vol. 2 (Samara, 2012).

Buranok S. O. 'Sozdanie obraza Kuybysheva v amerikanskoj presse', Chelovek i obshhestvo v uslovijah vojn i revoljucij: mater. III Vserossijskoj nauch. konf. (Samara, 2016).

Buranok S. O. Kuybyshev - zapasnaja stolica SSSR: obraz goroda v anglo-amerikanskom obshhestve 19411945 gg. (Samara, 2016).

Buranok S. O., Surzhik D. V., Belov D. A. "My" i "oni": Velikaja Otechestvennaja vojna v ocenke obshhestvennosti SShA i Velikobritanii: dokumenty i materialy (Samara, 2014).

Dimitrova P. 'Donesenija poslannika carstva Bolgarii v SSSR Ivana Stamenova kak istochnik o zhizni dipkorpusa v Kuybysheve (1941-1943 gg.)', Problemy izuchenija voennoj istorii: sb. st. Tretiej Vseros. nauch. konf. s mezhdunar. Uchastiem (Samara, 2015).

Khristoforov V. S. 'Amerikanskie diplomaty na rendez-vous s sovetskoj politikoj i kulturoj (1941-1945)', Quaestio Rossica, Vol. 4, no. 1, 2016.

Labutina T. L. 'Aktualnye problemy istoricheskoj imagologii: Istoriograficheskij obzor', Jugra, Sibir, Rossija: Politicheskie, jekonomicheskie, sociokulturnye aspekty proshlogo i nastojashhego: sb. nauch. st. Vseros. nauch. konf. s mezhdunar. uchastiem. (Nizhnevartovsk, 2015).

"My" $i$ "oni": Velikaja Otechestvennaja vojna v ocenkah anglo-amerikanskoj obshhestvennosti i sovremennoj istoriografii, by S. O. Buranok, Yu. A. Nikiforov, D. V. Surzhik, D. A. Belov and oth. (Samara, 2015).

Porshneva O.S. 'Istoricheskaja imagologija v sovremennoj rossijskoj istoriografii', Ural industrialnyj. Bakuninskie chtenija. Industrialnaja modernizacija Urala v XVIII-XXI vv.: XII Vseros. nauch. konf., Vol. 1 (Yekaterinburg, 2014).

Repinetskiy A. I. "'Zapasnaja stolitsa” na perekrestke vojny i diplomatii (g. Kuybyshev v gody Velikoj Otechestvennoj vojny)', Problemy izuchenija voennoj istorii: sb. st. Tretiej Vseros. nauch. konf. s mezhdunar. Uchastiem (Samara, 2015).

Senyavskiy A. S., Senyavskaya E. S. 'Istoricheskaja imagologija i problema formirovanija "obraza vraga" (na materialakh rossijskoj istorii XX v. )', Vestnik RUDN, Ser. Istorija Rossii, no. 2 (6), 2006.

Zakharchenko A. V. 'Voennyy parad v Kuybysheve 7 nojabrja 1941 g. - novye istochniki i interpretacii (po materialam GA RF)', Problemy izuchenija voennoj istorii: sb. st. Tretiej Vseros. nauch. konf. s mezhdunar. Uchastiem (Samara, 2015).

Cassidy H. Moscow Dateline: 1941-1943 (Boston, 1943).

Gilmor E. Me and My Russian Wife (New York, 1954). 